УДК 32

DOI $10.21661 / \mathrm{r}-473610$

\title{
И.А. Ланская
}

\section{СПЕЦИФИКА РОССИЙСКОЙ КОРРУПЦИИ (ПО МАТЕРИАЛАМ СОЦИОЛОГИЧЕСКИХ И СОЦИАЛЬНЫХ ИССЛЕДОВАНИЙ)}

Аннотация: одной из основных проблем России является высокий уровень коррупции практически во всех сферах жизни и развития общества. В данном исследовании приведены и проанализированы различные статистические и качественные данные, характеризующие развитие коррупџии в России.

Ключевые слова: коррупция, коррумпированность, специфика коррупщии, исследования коррупции, коррупщия в России.

\section{I.A. Lanskaya \\ SPECIFICITY OF RUSSIAN CORRUPTION (BASED ON SOCIOLOGICAL AND SOCIAL STUDIES)}

Abstract: one of the main problems of Russia is a high level of corruption in almost all spheres of life and development of society. In this study, various statistical and qualitative data characterizing the development of corruption in Russia are presented and analyzed.

Keywords: corruption, corruptness, specificity of corruption, corruption researches, corruption in Russia.

Коррупция в России является распространенным явлением и по данным Global Corruption Barometer коррумпированными являются многие сферы жизни российского общества. В частности, коррупции подвержены практически все властные структуры, включая исполнительную, судебную и законодательную власть, политические партии и организации, сферы здравоохранения и образования, армию, СМИ, бизнес (особенно крупный), НКО, а также религиозные учреждения. По сути, сложно назвать сферу жизни и развития общества в России с отсутствующей коррупцией. При этом, ключевой проблемой России является не 
только коррумпированность практически всех сфер развития, сколько экстремально высокий уровень коррумпированности большинства из них. Так, согласно экспертам из РБК, Генпрокуратура оценила ущерб от коррупции в России за последние 3 года в 130 млрд. рублей [11].

Основными нормативно-правовыми актами, призванными снизить уровень коррупции в российском обществе, являются Федеральный закон от 25 декабря 2008 г. №273-Ф3 «О противодействии коррупции» [14], а также серия указов президента и постановлений правительства, опубликованных после принятия данного закона.

В данном исследовании будут приведены и проанализированы различные статистические и качественные данные, характеризующие развитие коррупции в России.

В первую очередь необходимо отметить, что общий уровень коррумпированности российского общества очень высок. По сводному индексу коррупции страна находится на 135 месте в мире из 180 стран [7]. При этом, динамика изменения данного показателя крайне нестабильна (рис. 1) [6]. Индекс коррупционной прозрачности измеряется от 0 до 100. При этом, чем выше показатель, тем ниже оцененный уровень коррупции в стране. Данный показатель был создан в 1996 году. На тот момент уровень прозрачности деятельности различных организаций в России составлял 26 и снизился к 2000 году до 21. Затем в период с 2000 по 2004 возрос до 28, с 2004 по 2010 упал до 21, в то время как к 2016 году возрос до 29. 


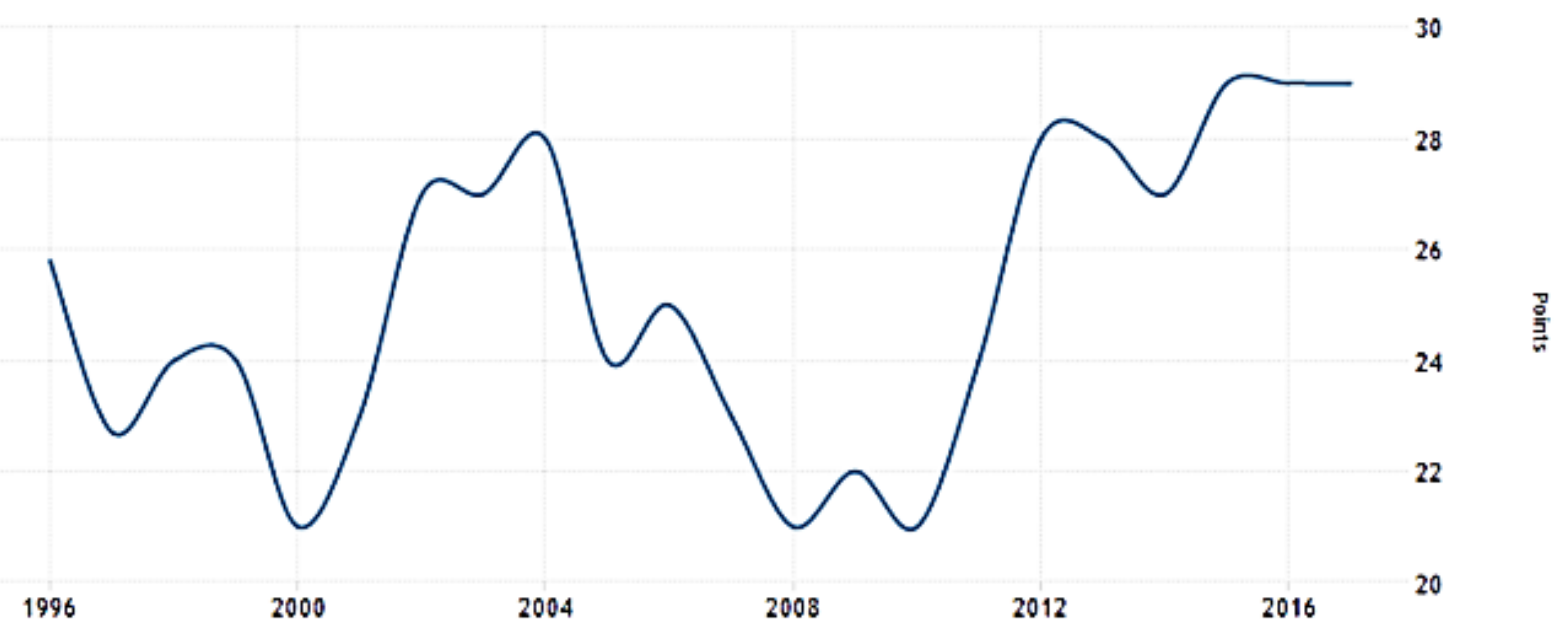

Рис. 1. Динамика индекса прозрачности (коррупционного индекса)

в России в 1996-2017 годах

Таким образом, можно сделать вывод о том, что коррупционная прозрачность в России всегда находилась на низком уровне, который периодически снижался до крайне низкого. Первый и основной антикоррупционный закон в России был принят в 2008 году, когда уровень коррупции был одним из наиболее высоких. Однако фактическое снижение ее уровня началось только с 2010 года. При этом, другие страны росли по данному показателю, что привело к его общему понижению рейтинга России.

Характеризуя коррумпированность основных сфер развития общества, необходимо привести оценки россиян за 2016 год, по данным Transparency International (таблица 1) [4].

Таблица 1

Оцененный уровень коррумпированности отдельных сфер жизни общества

\begin{tabular}{|l|c|}
\hline \multicolumn{1}{|c|}{ Сфера жсизни общества } & $\begin{array}{c}\text { Оиененный уровень } \\
\text { коррумпированности 2016 }\end{array}$ \\
\hline Чиновники и государственные служащие & 92 \\
\hline Полиция & 89 \\
\hline Судебная система & 84 \\
\hline Законодательная власть & 83 \\
\hline Политические партии & 77 \\
\hline Медицина & 75 \\
\hline Образование & 72 \\
\hline
\end{tabular}




\begin{tabular}{|l|c|}
\hline Армия & 70 \\
\hline СМИ & 59 \\
\hline Бизнес & 57 \\
\hline НКО & 45 \\
\hline Религиозные учреждения & 40 \\
\hline
\end{tabular}

Таким образом, коррупция практически во всех сферах жизни была оценена как высокая (выше 50\%) за исключением некоммерческих организаций и религиозных учреждений. При этом, даже для этих сфер уровень коррупции, по оценке населения, превышает 40\%. Во всех ветвях власти уровень коррупции зашкаливает и превышает оценку 80\%. При этом, 30-40\% населения России, контактировавшего с различными государственными органами, включая медицинские и образовательные учреждения, пришлось давать взятки [5].

Население России, характеризуя динамику изменения коррупции в российском обществе отвечало на 5 вопросов [4]:

1. Как изменился уровень коррупции в вашей стране за последние 2 года?

2. Насколько серьезной проблемой является коррупция в вашей стране?

3. Насколько текущее правительство управляет крупными организациями в своих собственных интересах?

4. Насколько эффективно проводится государственная борьба с коррупцией?

5. Насколько вы согласны с тем, что обычные люди могут помочь в борьбе с коррупцией?

В результате, было выявлено, что 50\% респондентов считают, что коррупция в российском обществе возросла, и 12\%, что она снизилась. $79 \%$ респондентов полагают, что коррупция представляет собой очень существенную проблему и $13 \%$, что довольно существенную. Согласно общественному мнению, $85 \%$ населения полагают, что текущее правительство подчинило крупнейшие компании страны полностью или в очень большой мере. При этом, $77 \%$ уверены, что антикоррупционные действия правительства варьируются от крайне неэффективных до неэффективных. В данном вопросе не помогает даже то, что за последние 3 года в России за коррупцию посадили 45 тысяч человек [11], а также 
такие громкие судебные процессы как дело Роскосмоса, Оборонсервиса, Росагролизинга, РусГидро, Росреестра, Росрыболовства, Хорошавина, космодрома «Восточный», Вячеслава Гайзера, Никиты Белых, Алексея Улюкаева, «Воентелекома» и Гамидова [12]. При этом, 58\% населения считают, что обычные граждане никак не могут повлиять на снижение уровня коррупции в стране.

В попытках объяснить высокий уровень коррупции в различных странах, Transparency International предложила регрессионную модель, связывающую прозрачность общественных отношений с уровнем участия граждан в общественном развитии [3]. Данная модель для России является в целом валидной, что показывают результаты формирования индекса демократии подразделением журнала The Economist [2] (таблица 2).

Таблица 2

Индекс демократии в России в 2006-2016 годах

\begin{tabular}{|l|c|c|c|c|c|c|}
\hline \multicolumn{1}{|c|}{ Годы } & 2006 & 2008 & 2010 & 2012 & 2014 & 2016 \\
\hline Ранг (место в мире) & 102 & 107 & 107 & 122 & 132 & 134 \\
\hline Общее баллы & 5,02 & 4,48 & 4,26 & 3,74 & 3,39 & 3,24 \\
\hline $\begin{array}{l}\text { Выборный процесс и политический плю- } \\
\text { рализм }\end{array}$ & 7 & 5,25 & 5,25 & 3,92 & 3,08 & 2,67 \\
\hline Функционирование государства & 3,21 & 2,86 & 3,21 & 2,86 & 2,86 & 2,5 \\
\hline Политическое участие & 5,56 & 5,56 & 5 & 5 & 5 & 5 \\
\hline Политическая культура & 3,75 & 3,75 & 3,13 & 2,5 & 2,5 & 2,5 \\
\hline Гражданские свободы & 5,59 & 5 & 4,71 & 4,41 & 3,53 & 3,53 \\
\hline
\end{tabular}

В первую очередь, необходимо отметь, что позиция России в данном индексе существенно снизилась в период с 2006 по 2016 год. При этом, согласно общему количеству баллов она перешла из группы стран с развивающейся демократией в группу недемократических. Важно подчеркнуть, что в 2006 году выборный процесс и политический плюрализм оценивался международными экспертами на 7 баллов, в то время как в 2016 на 3,24. Схожую динамику, однако, менее острую продемонстрировали и другие показали, в частности гражданские свободы оценивались в 2006 году на 5,59 баллов, а в 2016 - на 3,53. Общие тенденции во всех пяти областях, оцениваемых в данном индексе, имели тенденцию к снижению, тем не менее, динамику показателей нельзя назвать равномерной. 
В первую очередь, необходимо отметить общую неравномерность изменений. Так, существенный спад в периоды 2006-2008 годов и 2010-2012 годов чередовался с более плавным снижением в остальное время.

Из приведенной таблицы становится очевидным, что политическое участие, политическая культура и гражданские свободы, а также их изменения во многом определяют коррупционную прозрачность в России.

Помимо всего вышесказанного необходимо отдельно отметить коррумпированность государственных расходов на военные нужды. В частности, 2,7 млрд рублей расходов на военные нужды относятся к категории закрытых, отчеты по которым отсутствуют [1]. При этом, только 1/5 часть расходов на военные нужды осуществляются на конкурентной основе. В то время как подавляющее большинство полностью засекречено.

Тем не менее, несмотря на множественные проблемы с коррупцией в России, существуют и положительные тенденции.

Во-первых, с 2014 года по 2016 существенно снизилась коррумпированность корпоративного сектора. Так, доля компаний у которых вымогали взятки снизилась с 41 до 21 процента (при среднем в мире - 13\%). При этом, доля компаний, проигравших конкурентам, заплатившим взятку, сократилась с 42 до 17\%, что практически соответствует среднемировому уровню в $15 \%$ [10].

Одновременно стоит отметить, что уровень коррупции в российском бизнесе сравнялся в 2016 году с аналогичным показателем для США [13]. Кроме того, 31 из ТОП 200 крупнейших компаний России предоставляет достаточно прозрачную отчетность, согласно исследованию, проведенному Transparency International по итогам 2017 года [9].

Таким образом, можно сказать, что уровень коррупции в России, оставаясь по прежнему высоким, не равномерен в различных сферах развития общества. В частности, наиболее низкий уровень коррупции наблюдается в бизнес-среде. Кроме того, наблюдается его общее незначительное снижение. Тем не менее, по оценке граждан страны он остается слишком высоким, тенденция к его снижению очень слабой, а уровень влияния государства на бизнес чрезвычайно 
высоким. Стоит также отметить, что во многом высокий уровень коррупции детерминирован ограничениями свободы слова и снижением политической культуры населения. Слабо выраженная гражданская позиция, не способствует снижению уровня коррупции. При этом, введение за последние несколько лет множества ограничений, таких как блокировка телеграмма [8], не позволяет формироваться гражданской позиции и во многом подавляет ее. Таким образом, невозможно прогнозировать существенное снижение уровня коррупции в ближайшие годы в России.

\section{Список литературы}

1. Corruption risks at the Russian Ministry of Defence. Conflicts of interest // Transparency international [Электронный pecypc]. - Режим доступа: https://transparency.org.ru/projects/TI_Defence_Press_Eng.pdf (дата обращения: 18.05.2018).

2. Democracy index. Economist Intelligence Unit [Электронный ресурс]. - Peжим доступа: https://www.eiu.com/topic/democracy-index (дата обращения: 30.03.2018).

3. Digging deeper into corruption, violence against journalists and active civil society // Transperency International [Электронный pecypc].- Режим доступа https://www.transparency.org/news/feature/digging_deeper_into_corruption_violence_ against_journalists (дата обращения: 18.05.2018).

4. National results. Russia // Transparency international [Электронный ресурс]. - Режим доступа https://www.transparency.org/gcb2013/country?country=russia (дата обращения: 18.05.2018).

5. Percentage of people who paid a bribe when they came into contact with a public service in the 12 last months. People and corruption: citizen's voices from around the world. Global corruption barometer [Электронный ресурс]. - Режим доступа https://www.transparency.org/research/gcb/gcb_2015_16/0 (дата обращения: 18.05.2018).

6. Russia Corruption Index // Trading economics [Электронный ресурс]. - Peжим доступа: https://tradingeconomics.com/russia/corruption-index (дата обращения: 18.05.2018). 
7. Russia Ranks 135th in Transparency International's World Corruption Index // The Moscow Times [Электронный pecypc].- Режим доступа: https://themoscowtimes.com/news/russia-ranks-135-in-transparency-internationals-world-corruption-index-60605 (дата обращения: 18.05.2018).

8. Russia: Telegram block leads to widespread assault on freedom of expression online // Transparency International [Электронный pecypc]. - Режим доступа: https://www.transparency.org/news/pressrelease/russia_telegram_block_leads_to_widespread_assault_on_freedom_of_expression (дата обращения: 18.05.2018).

9. Transparency in Corporate Reporting: Assessing the Russia's Largest Companies // Transparency International [Электронный pecypc].- Режим доступа: https://transparency.org.ru/special/trac2018russia/en/ (дата обращения: 18.05.2018).

10. В России оценили уровень коррупции в стране: опубликована инфографика // Апостроф [Электронный ресурс]. - Режим доступа: https://apostrophe.ua/ news/world/ex-ussr/2017-03-29/v-rossii-otsenili-uroven-korruptsii-v-strane-opublikova na-infografika/91627 (дата обращения: 18.05.2018).

11. Генпрокуратура оценила ущерб от коррупции в России за 2,5 года // РБК [Электронный ресурс]. - Режим доступа: https://www.rbc.ru/society/09/08/2017/ 598b48a99a79471ae35f7433 (дата обращения: 18.05.2018).

12. Коррупция в России // Руксперт [Электронный ресурс]. - Режим доступа: http://ruxpert.ru/\%D0\%9A\%D0\%BE\%D1\%80\%D1\%80\%D1\%83\%D0\%BF\%D1\%86\% D0\%B8\%D1\%8F_\%D0\%B2_\%D0\%A0\%D0\%BE\%D1\%81\%D1\%81\%D0\%B8\%D0\% B8\#.D0.A0.D0.B5.D0.B7.D0.BE.D0.BD.D0.B0.D0.BD.D1.81.D0.BD.D1.8B.D0.B5_.D 0.B4.D0.B5.D0.BB.D0.B0 (дата обращения: 18.05.2018).

13. Россия и США сравнялись по уровню коррупции в бизнесе // РБК [Электронный ресурс].- Режим доступа: https:/www.rbc.ru/economics/22/04/2016/ 57192b039a794712a045dfd0 (дата обращения: 18.05.2018).

14. Федеральный закон от 25.12.2008 г. №273-Ф3 «О противодействии коррупции» // СПС КонсультантПлюс.

\section{References}

8 https://interactive-plus.ru

Содержимое доступно по лицензии Creative Commons Attribution 4.0 license (CC-BY 4.0) 
1. Corruption risks at the Russian Ministry of Defence. Conflicts of interest. Transparency international. Retrieved from https://transparency.org.ru/projects/TI_Defence_Press_Eng.pdf

2. Democracy index. Economist Intelligence Unit. Retrieved from https://www.eiu.com/topic/democracy-index

3. Digging deeper into corruption, violence against journalists and active civil society. Transperency International. Retrieved from https://www.transparency.org/news/feature/digging_deeper_into_corruption_violence_against_journalists

4. National results. Russia. Transparency international. Retrieved from https://www.transparency.org/gcb2013/country?country=russia

5. Percentage of people who paid a bribe when they came into contact with a public service in the 12 last months. People and corruption: citizen's voices from around the world. Global corruption barometer. Retrieved from https://www.transparency.org/ research/gcb/gcb_2015_16/0

6. Russia Corruption Index. Trading economics. Retrieved from https://tradingeconomics.com/russia/corruption-index

7. Russia Ranks 135th in Transparency International's World Corruption Index. The Moscow Times. Retrieved from https://themoscowtimes.com/news/russia-ranks135-in-transparency-internationals-world-corruption-index-60605

8. Russia: Telegram block leads to widespread assault on freedom of expression online. Transparency International. Retrieved from https://www.transparency.org/news/pressrelease/russia_telegram_block_leads_to_widespread_assault_on_ freedom_of_expression

9. Transparency in Corporate Reporting: Assessing the Russia's Largest Companies. Transparency International. Retrieved from https://transparency.org.ru/special/trac2018russia/en/

10. V Rossii otsenili uroven' korruptsii v strane: opublikovana infografika. Apostrof. Retrieved from https://apostrophe.ua/news/world/ex-ussr/2017-03-29/v-rossii-otsenili-uroven-korruptsii-v-strane-opublikovana-infografika/91627 
11. Genprokuratura otsenila ushcherb ot korruptsii v Rossii za 2,5 goda. $R B K$. Retrieved from https://www.rbc.ru/society/09/08/2017/598b48a99a79471ae35f7433

12. Korruptsiia v Rossii. Rukspert. Retrieved from http://ruxpert.ru/\%D0\% 9A\%D0\%BE\%D1\%80\%D1\%80\%D1\%83\%D0\%BF\%D1\%86\%D0\%B8\%D1\%8F_\%D 0\%B2_\%D0\%A0\%D0\%BE\%D1\%81\%D1\%81\%D0\%B8\%D0\%B8\#.D0.A0.D0.B5.D0. B7.D0.BE.D0.BD.D0.B0.D0.BD.D1.81.D0.BD.D1.8B.D0.B5_.D0.B4.D0.B5.D0.BB.D $0 . \mathrm{B} 0$

13. Rossiia i SShA cravnialis' po urovniu korruptsii v biznese. $R B K$. Retrieved from https://www.rbc.ru/economics/22/04/2016/57192b039a794712a045dfd0

14. Federal'nyi zakon ot 25.12.2008 g. 273-FZ "O protivodeistvii korruptsii". SPS Konsul'tantPlius.

Ланская Ирина Андреевна - магистрант ФГАОУ ВО «Национальный исследовательский университет «Высшая школа экономики», Россия, Москва.

Lanskaya Irina Andreevna - undergraduate of the National Research University «Higher School of Economics», Russia, Moscow. 